\title{
Chromatin topology reorganization and transcription repression by PML-RARa in acute promyeloid leukemia
}

Ping Wang ${ }^{1}$, Zhonghui Tang ${ }^{1,2}$, Byoungkoo Lee ${ }^{1}$, Jacqueline Jufen Zhu ${ }^{1,3}$, Liuyang Cai ${ }^{1}$, Przemyslaw Szalaj ${ }^{4}$, Simon Zhongyuan Tian ${ }^{1}$, Meizhen Zheng ${ }^{1}$, Dariusz Plewczynski ${ }^{4}$, Xiaoan Ruan ${ }^{1}$, Edison T. Liu' ${ }^{1}$, Chia-Lin Wei ${ }^{1}$ and Yijun Ruan ${ }^{1,3^{*}}$

\author{
* Correspondence: vijun.ruan@jax. \\ org \\ ${ }^{1}$ The Jackson Laboratory for \\ Genomic Medicine, 10 Discovery \\ Drive, Farmington, CT 06030, USA \\ ${ }^{3}$ Department of Genetics and \\ Genome Sciences, University of \\ Connecticut Health Center, 400 \\ Farmington Avenue, Farmington, $C T$ \\ 06030, USA \\ Full list of author information is \\ available at the end of the article
}

\begin{abstract}
Background: Acute promyeloid leukemia (APL) is characterized by the oncogenic fusion protein PML-RARa, a major etiological agent in APL. However, the molecular mechanisms underlying the role of PML-RARa in leukemogenesis remain largely unknown.

Results: Using an inducible system, we comprehensively analyze the 3D genome organization in myeloid cells and its reorganization after PML-RARa induction and perform additional analyses in patient-derived APL cells with native PML-RARa. We discover that PML-RARa mediates extensive chromatin interactions genome-wide. Globally, it redefines the chromatin topology of the myeloid genome toward a more condensed configuration in APL cells; locally, it intrudes RNAPII-associated interaction domains, interrupts myeloid-specific transcription factors binding at enhancers and super-enhancers, and leads to transcriptional repression of genes critical for myeloid differentiation and maturation.

Conclusions: Our results not only provide novel topological insights for the roles of PML-RARa in transforming myeloid cells into leukemia cells, but further uncover a topological framework of a molecular mechanism for oncogenic fusion proteins in cancers.
\end{abstract}

Keywords: PML-RARa, ChIA-PET, 3D genome architecture, CTCF, RNA polymerase II (RNAPII), Transcription factor (TF), Transcriptional regulation, Super-enhancer (SE)

\section{Introduction}

Leukemias are often triggered by chromosomal rearrangements, such as translocations and inversions, which can generate oncogenic fusion transcription factors $[1,2]$. A hallmark in acute promyeloid leukemia (APL) is a chromosomal translocation that fuses the promyelocytic leukemia gene $(P M L)$ on chromosome 15 and the retinoic acid receptor alpha gene $(R A R \alpha)$ on chromosome 17 into a fusion gene $P M L-R A R \alpha[3,4]$. This translocation, denoted as $\mathrm{t}(15 ; 17)(\mathrm{q} 24 ; \mathrm{q} 21)$,

(c) The Author(s). 2020 Open Access This article is licensed under a Creative Commons Attribution 4.0 International License, which permits use, sharing, adaptation, distribution and reproduction in any medium or format, as long as you give appropriate credit to the original author(s) and the source, provide a link to the Creative Commons licence, and indicate if changes were made. The images or other third party material in this article are included in the article's Creative Commons licence, unless indicated otherwise in a credit line to the material. If material is not included in the article's Creative Commons licence and your intended use is not permitted by statutory regulation or exceeds the permitted use, you will need to obtain permission directly from the copyright holder. To view a copy of this licence, visit http//creativecommons.org/licenses/by/4.0/. The Creative Commons Public Domain Dedication waiver (http://creativecommons.org/publicdomain/zero/1.0/) applies to the data made available in this article, unless otherwise stated in a credit line to the data. 
occurs in $98 \%$ of APL patients, and this fusion gene encodes a fusion protein PML-RAR $\alpha$, considered as a major etiological agent of APL. In normal myeloid cells, RAR $\alpha$ (a nuclear receptor and transcription factor) plays important roles in myelopoiesis, especially in granulocytic and monocytic differentiation programs $[5,6]$. However, the fusion protein PML-RAR $\alpha$ in APL has been suggested to compete with endogenous RAR $\alpha$ for binding at the same RA response elements (RAREs), which in turn leads to repression of normal RAR $\alpha$ signaling in a dominant-negative manner [7]. It has also been hinted that PML-RAR $\alpha$ could predominantly target promoters regulated by transcription factor PU.1 through protein-protein interactions between PU.1 and RAREh binding sites genome-wide [8]. Early studies have suggested that PML-RAR $\alpha$ may also abnormally recruit a histone deacetylase (HDAC) and/or polycomb repressive complexes (PRCs) to target genes important in hematopoietic differentiation $[9,10]$, indicating that PMLRAR $\alpha$ may have a role in altering chromosome configuration during APL genesis. Taken together, these investigations suggest a significant range of genome-wide restructuring induced by PML-RAR $\alpha$; however, how the comprehensive molecular mechanisms underlie the role of PML-RAR $\alpha$ in leukemogenesis remains largely unknown.

Over the last decade, it has become clear that the human genomes are folded in complex 3-dimensional (3D) organizations in nuclei and that 3D chromatin architectures may be important in the higher-order regulation of transcription regulation [11]. Several studies have hinted that chromosomal rearrangements in acute myeloid leukemia (AML) with inv. (3)/t(3,3) lead to long-range interactions characterized by the 3D repositioning of a GATA2 enhancer to the EVI1 promoter to ectopically activate EVI1, which can cause dysregulation of both genes, with AML as the outcome [12,13]. Another study has shown that the deletion of insulated chromatin domain boundaries could activate proto-oncogene expression through aberrant distal regulatory elements, thereby contributing to $\mathrm{T}$ cell acute lymphoblastic leukemia (T-ALL) [14]. Although these reports together indicated that chromatin configuration change might be an important feature in the transformation of normal cells into leukemic cells by oncogenic fusion proteins, specific evidence is lacking.

Considering that RAR $\alpha$ binds directly to DNA genome-wide, we posit that the oncogenic fusion protein PML-RAR $\alpha$ may also possess chromatin interaction properties, and alter the 3D genome topology as a critical event during leukemogenesis. To this end, we comprehensively analyzed normal myeloid cells with inducible PML-RAR $\alpha$, and patient-derived APL cells with native PMLRAR $\alpha$, to determine the roles of PML-RAR $\alpha$ in $3 \mathrm{D}$ genome organization and transcription regulation, using integrative approaches including ChIA-PET for chromatin interactions, ChIP-seq for epigenomic states, and RNA-seq for transcriptional outputs. We discovered that PML-RAR $\alpha$ mediated extensive longrange chromatin interactions genome-wide, distorted the established chromosomal folding topology in normal myeloid cells, and specifically repressed transcription of genes that are important to myeloid differentiation and maturation, together suggesting a topological mechanism for PML-RAR $\alpha$ in leukemogenesis. 


\section{Results}

Genome-wide chromatin interactions in normal myeloid cells and APL cells

To investigate the mechanisms through which PML-RAR $\alpha$ leads to the development of promyelocytic leukemia phenotypes in myeloid cells, we employed a well-established PR9 cell line, which is derived from U937 myeloid precursors at the promonocytic stage. PR9 cell line possesses normal endogenous PML and RAR $\alpha$ genes but also contains a transgenic construct inducible for PML-RAR $\alpha$ expression via the addition of ZnSO4. Upon induction, the expression of PML-RAR $\alpha$ in PR9 drives the cells to develop promyelocytic leukemia phenotypes [15]. It has also been shown that the protein expression level of PML-RAR $\alpha$ in ZnSO4-treated PR9 cells is comparable to that in APL patient-derived NB4 cells [8]. Hence, by comparing PR9 cells under normal conditions (without PML-RAR $\alpha$ protein) with PR9 cells under $\mathrm{ZnSO} 4$ induction conditions (with induced PML-RAR $\alpha$ ), we can investigate the dynamic changes of the myeloid genome mediated by the nascent fusion protein PML-RAR $\alpha$ in PR9 cells (Fig. 1a).

To map the PML-RAR $\alpha$-initiated chromatin interactions to the myeloid genome, we performed ChIA-PET experiments using anti-PML and anti-RAR $\alpha$ antibodies in both PR9 and PR9+Zn cells (Additional file 1: Table S1). Although the PR9 cells carry a transgenic PML-RAR $\alpha$ construct, they would not express PML-RAR $\alpha$ fusion protein without $\mathrm{ZnSO} 4$ induction and should retain the endogenous $P M L$ and $R A R \alpha$ genes and normal expression of native PML and RAR $\alpha$ proteins. After $\mathrm{ZnSO} 4$ treatment, hereafter referred to as $\mathrm{PR} 9+\mathrm{Zn}$ cells, the PR9+Zn cells should acquire the induced PML-RAR $\alpha$ protein while still retaining the native PML and RAR $\alpha$ proteins. Therefore, the PML- and RAR $\alpha$-enriched ChIA-PET experiments were expected to detect both of the native proteins and the induced PML-RAR $\alpha$ in PR9+Zn cells, but only the native proteins in PR9 cells. As shown in the 2D chromatin contact profiles of the ChIA-PET data (Fig. 1b), the RAR $\alpha$ ChIA-PET experiment generated distinctive and typical chromatin contact data that mapped along the $2 \mathrm{D}$ contact diagonal, whereas the PML ChIA-PET experiment produced no meaningful chromatin contact data. This was expected, as RAR $\alpha$ is a DNA-binding transcription factor, and PML does not interact with chromatin in the nuclei. In contrast, we obtained extensive chromatin contact data in both the PML and RAR $\alpha$ ChIA-PET experiments, from PR9+Zn cells (Fig. 1b). The striking similarity of chromatin contact patterns exhibited by these two ChIA-PET experiments in PR9+Zn cells using different antibodies (anti-PML and anti-RAR $\alpha$ ) validates that the induced fusion protein PML-RAR $\alpha$ mediated new chromatin interactions in PR9+Zn cells.

To systematically investigate the impact of PML-RAR $\alpha$ on the genomes, it is necessary to characterize the $3 \mathrm{D}$ genome organization in both normal myeloid cells and APL cells. Therefore, we first generated high-quality CCCTC-binding factor (CTCF)enriched ChIA-PET data (Additional file 1: Table S1) and mapped the higher-order chromosomal folding architectures and the detailed chromatin domain topology mediated by CTCF in PR9 cells and PR9 cells with induced PML-RAR $\alpha$ expression via the addition of ZnSO4. Overall, these two CTCF datasets were highly correlated (Additional file 2: Figure S1a-b), and the 2D contact profiles appeared to be identical (Fig. 1c), indicating that the $\mathrm{ZnSO} 4$ treatment did not directly alter the CTCFmediated chromatin interactions in the myeloid genome. 
a

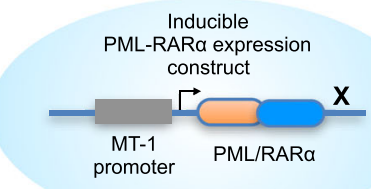

PR9

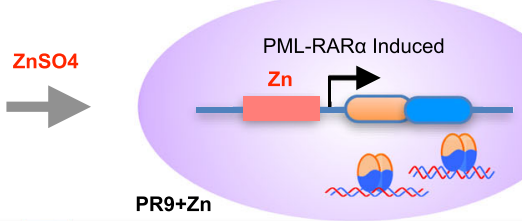

ChIA-PET (CTCF, RNAPII, PML, RARa), ChIP-seq (histone marks, TFs), RNA-seq

b

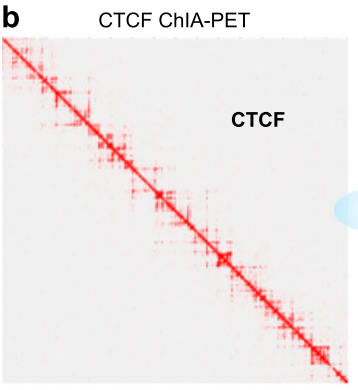

chr1: $18,000,000-26,000,000$

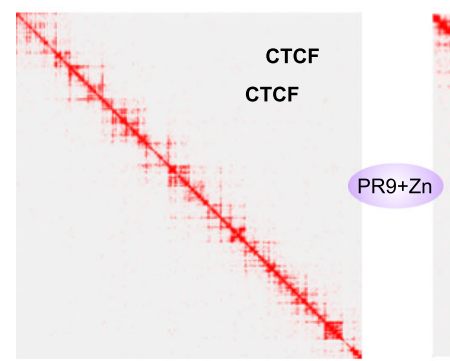

e

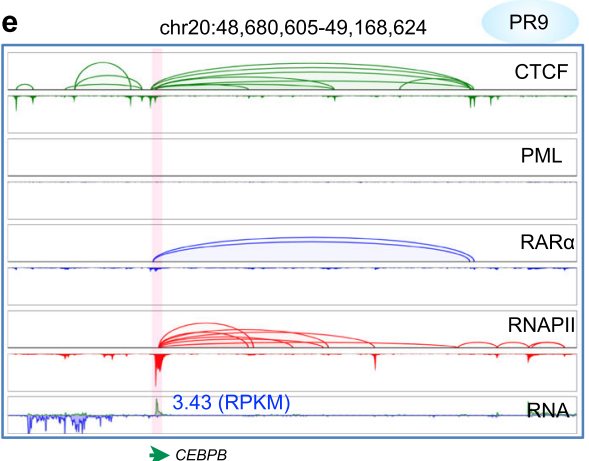

Fig. 1 (See legend on next page.)

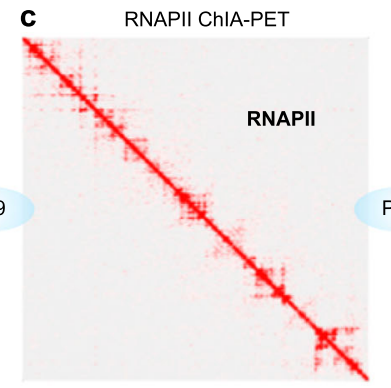

chr20: $1,700,000-6,200,000$
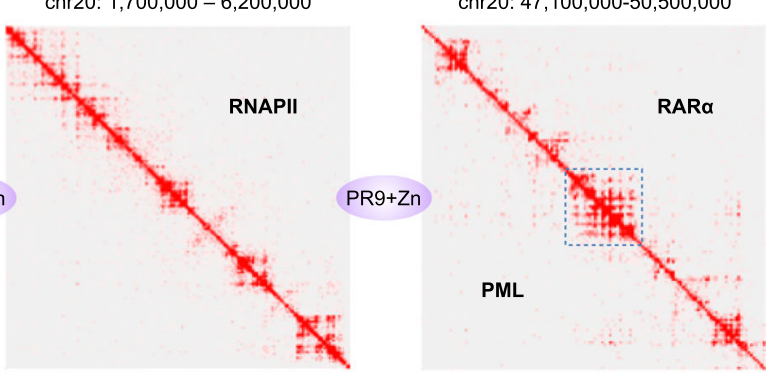

d PML, RAR $\alpha$ ChIA-PET

PR9

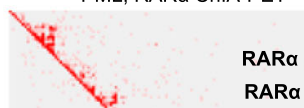

PML

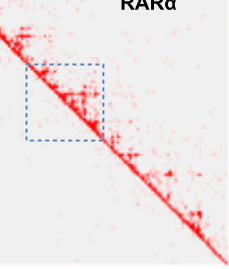

$\mathrm{hr} 20: 48,680,605-49,168,624$

$P R 9+Z n$

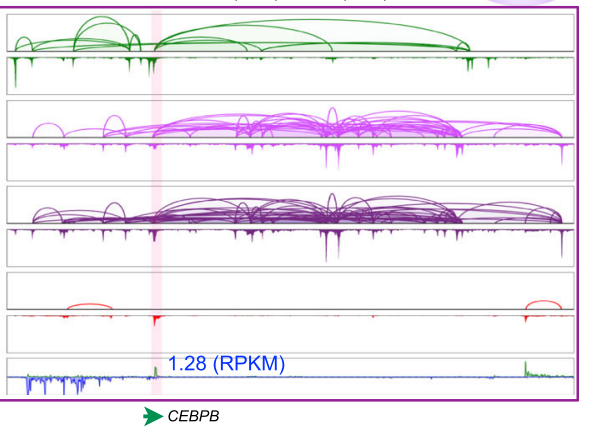

$\rightarrow C E B P B$ 
(See figure on previous page.)

Fig. 1 Mapping of 3D epigenome organizations in myeloid cells with inducible PML-RARa. a Schematic of experimental designs using an inducible system. PR9 cells contain an inducible construct of the fusion gene PML-RARa. Upon ZnSO4 induction, the fusion gene will be activated, and the PML-RARa protein is expressed and interacts with the myeloid genome. Both PR9 and PR9+Zn cells were analyzed by ChIA-PET, ChIP-seq, and RNA-seq to map the 3D epigenomes. b 2D chromatin contact maps of the PML and RARa ChIA-PET data from PR9 (top) and PR9+Zn (bottom) cells. To be noted, PML ChIA-PET did not produce meaningful data, while the RARa ChIA-PET generated abundant data mapping RARa-mediated chromatin interactions in PR9 cells (top). However, both PML and RARa experiments in PR9+Zn cells produced equal amounts of data with the same patterns, indicating the detection of chromatin interactions mediated by the fusion protein PML-RARa. The boxed segments were zoomed in for details in e. c 2D chromatin contact maps of the CTCF ChIA-PET data from PR9 (top) and PR9+Zn (bottom) cells. $\mathbf{d}$ 2D chromatin contact maps of the RNAPII ChIA-PET data from PR9 (top) and PR9+Zn (bottom) cells. e Screenshots of browser views displaying a genomic segment at CEBPB loci in chr20, exemplifying the chromatin interactions detected by ChIA-PET using PML, RARa, CTCF, and RNAPII antibodies in PR9 (left) and PR9+Zn (right) cells. As shown, the CTCF data (green) exhibited the same patterns and intensity in both PR9 and PR9+Zn cells; no PML data (pink) in PR9 cells, but extensive data in PR9+Zn cells; weak RARa signals in PR9 but strong and abundant (purple) in PR9+Zn; strong RNAPII (red) binding at the CEBPB gene locus and interaction loops to enhancer sites in PR9 cells, but absent in PR9+Zn cells. The RNA-seq data showing that CEBPB is expressed in PR9 cells $(R P K M=3.43)$, but reduced by twofold in PR9+Zn cells $(R P K M=1.28)$

In addition, we also performed RNA polymerase II (RNAPII) ChIA-PET experiments (Additional file 1: Table S1) to map transcriptional chromatin interactions involving promoters and enhancers for active genes in PR9 and PR9+Zn cells. Globally, the two RNAPII ChIA-PET datasets appeared highly comparable (Fig. 1d and Additional file 1: Figure S1c-d); however, locally, we observed a significant difference (Fig. 1e). For example, at the locus of the gene $C E B P B$ (encoding an important transcription factor for myeloid differentiation), it is observed that although the CTCF-mediated chromatin interactions in PR9 and PR9+Zn cells were very similar, the overwhelming chromatin contacts mediated by PML-RAR $\alpha$ (detected by PML and RAR $\alpha$ ChIA-PET data) in $\mathrm{PR} 9+\mathrm{Zn}$ cells appeared to overwrite the normal chromatin folding architecture predefined by CTCF around the CEBPB (Fig. 1e). Remarkably, the extensive RNAPII occupancy at the $C E B P B$ promoter and the abundant looping contacts from the promoter to enhancers shown in PR9 cells (Fig. 1e, left) were abolished in PR9+Zn cells (Fig. 1e, right). Consequently, the transcription of $C E B P B$ was repressed in PR9+Zn cells as measured by RNA-seq data. Together, these observations imply that PML-RAR $\alpha$ could potentially have a strong impact on the chromatin folding architecture and transcription regulation in myeloid cells.

\section{Topological reorganization of the myeloid genome by PML-RARa}

To meticulously characterize the myeloid 3D genome organization and the impact of PML-RAR $\alpha$ on myeloid genome topology, we first comprehensively characterized the CTCF ChIA-PET data in PR9 and PR9+Zn cells for their 3D chromatin organization, which reflected the native genome status of the myeloid genome. Because the two CTCF datasets were highly consistent (Fig. 1c) and that the ZnSO4 treatment in PR9 cells did not significantly change the CTCF chromatin interaction domains in the myeloid genome, we combined the two CTCF ChIA-PET datasets for increased data coverage to create a reference topological map mediated by CTCF of the myeloid genome in PR9 cells. Based on the connectivity of the CTCF loop clusters, we identified 2699 CTCF contact domains (CCDs) covering the majority of the myeloid genome (Fig. 2a), 


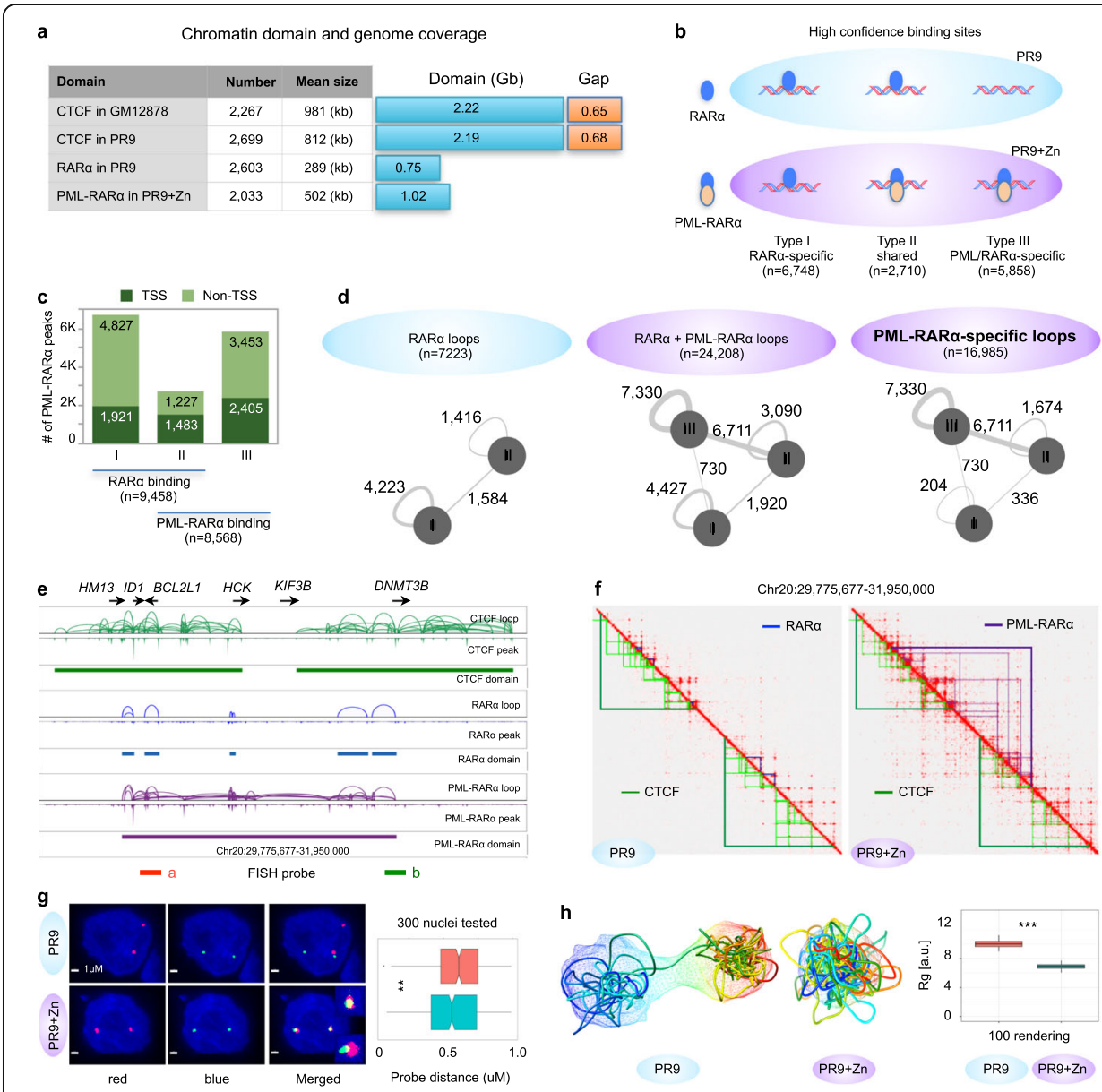

Fig. 2 Reorganization of chromatin topology by PML-RARa-mediated chromatin interactions. a Chromatin domains and genomic coverages by CTCF (combined data in PR9 and PR9+Zn cells), RARa (PR9), and PMLRARa (combined data in PR9+Zn). The summary table shows domain numbers and size of interaction domains. CTCF data from B-lymphoblastoid cells (GM12878) was given as a reference. b Schematic of RARa and PML-RARa binding sites detected in PR9 and PR9+Zn cells detected by RARa and PML ChIA-PET experiments. RARa-specific (I), RARa and PML shared (II), and PML-RARa-specific binding sites were identified based on the combination patterns of the data in both PR9 and PR9+Zn cells. c Characterized RARa and PML-RARa binding sites in relation to TSS of genes. $\mathbf{d}$ Identification and classification of RARaand PML-RARa-associated chromatin interactions in PR9 and PR9+Zn cells. Three types of RARa and PMLRARa binding sites (b) involved in interactions are indicated as circles. The interactions between two sites are indicated with lines. The thickness of the lines corresponds to the number of interactions. Numbers of chromatin interactions in each category are given alongside the lines. e Screenshot of genome browser view of chromatin interaction loop, binding peak, and chromatin interaction domain for CTCF (green), RARa (blue), and PML-RARa (purple) at the ID1-HCK locus. Binding and looping signals for each protein factor were normalized. $\mathbf{f}$ Integrated 2D chromatin contact maps for the genomic segment (the same as in e) on chr20 for CTCF, RARa, and PML-RARa ChIA-PET data from PR9 and PR9+Zn cells. The red signals in the contact maps were from the combined CTCF and RARa data (left, PR9 cells) and the combined CTCF, RARa, and PML data (right, PR9+Zn cells). Light green and dark green triangles depict CTCF loop and CCD, respectively; light blue and dark blue triangles depict RARa loops and domains; light and dark purple depict PML-RARa loops and domains. Red triangles indicate RNAPII-mediated loops and domains. g 3D DNA-FISH validation. Two probes (red and blue) were designed at the corresponding position in the two separated CTCF domains as shown in e. Left panel: example 3D DNA-FISH images of separated and merged views for the two probes ("a" in red, "b" in green) were shown in both PR9 and PR9+Zn cells. Right panel: boxplot of spatial distance between the two probes measured microscopically from 300 nuclei in each of the PR9 and PR9+Zn cells. Mann-Whitney $U$ test was used to test the difference. ${ }^{* *} p<0.01 . \mathbf{h} 3 \mathrm{D}$ chromatin folding rendering. Simulated 3D models of average structure and ensemble cloud in PR9 (left) and PR9+Zn (middle) using the data in the corresponding region in $\mathbf{f}$. Boxplot of the radial diameter of simulated 3D models. K-S test was used to test the differences. ${ }^{* *} p<2.2 \mathrm{e}-16$ 
which is comparable with the CCDs previously detected in the genome of Blymphoblastoid GM12878 cells [16].

We then analyzed the RAR $\alpha$ ChIA-PET and PML ChIA-PET data in PR9 and PR9+Zn cells. The analysis of the RAR $\alpha$ ChIA-PET data in PR9 cells to detect endogenous RAR $\alpha$ is straightforward, the same as we did for CTCF and RNAPII ChIAPET data. However, in PR9+Zn cells, it is complicated, because both of the native RAR $\alpha$ and the induced PML-RAR $\alpha$ were expressed. Therefore, to distinguish the PMLRAR $\alpha$-associated chromatin contacts from the RAR $\alpha$-associated contacts, we dissected the ChIA-PET data (RAR $\alpha$ ) from PR9 cells and the data (PML and RAR $\alpha$ ) from PR9+Zn cells based on binding sites and chromatin loops. Hereby, we first analyzed the protein binding sites of the ChIA-PET data in both PR9 (with native RAR $\alpha$ ) and PR9+Zn cells (with native RAR $\alpha$ and induced PML-RAR $\alpha$ ). To filter for highconfidence data, we defined a reliable binding site that was supported by at least two of the three independent ChIA-PET datasets (RAR $\alpha$ data in PR9, RAR $\alpha$ in PR9+Zn, and PML in PR9+Zn). Using this criterion, we identified 9458 RAR $\alpha$ binding sites in PR9 cells and 8568 PML-RAR $\alpha$ binding loci in PR9+Zn cells (Fig. 2b). The majority of the RAR $\alpha$ binding sites $(6748 ; 71 \%)$ were RAR $\alpha$-specific (detected in both PR9 and PR9+Zn cells, but not in PML data in PR9+Zn cells). However, there were 2710 (29\%) RAR $\alpha$ binding sites in PR9 cells that were also found in PML and RAR $\alpha$ data in PR9+Zn cells, suggesting a possible co-occupancy or a competition mode at those loci by the native RAR $\alpha$ and the induced PML-RAR $\alpha$. In addition, we identified 5858 PML-RAR $\alpha-$ specific loci in PR9+Zn cells (Fig. 2b). Overall, both the native RAR $\alpha$ and fusion protein PML-RAR $\alpha$ demonstrated similar genome-wide chromatin binding capacity (9458 vs. 8568). Proportionally, 28\% (1921/6748) of the RAR $\alpha$-specific binding sites were located proximal to the gene transcription start sites (TSS), whereas $41 \%(2405 / 5858)$ of the PML-RAR $\alpha$-specific binding sites and 55\% (1483/2719) of PML-RAR $\alpha$ sites colocalized with RAR $\alpha$ sites were proximal to TSS (Fig. 2c). This observation suggests an increased tendency for PML-RAR $\alpha$ to target gene promoters for the alteration of gene transcription regulation, in addition to binding at non-genic regions to impact chromatin architecture.

Next, we analyzed the chromatin contact loops mediated by RAR $\alpha$ or PML-RAR $\alpha$, which identified 7223 high-confidence loops by RAR $\alpha$ in PR9 cells, and 24,208 loops in $\mathrm{PR} 9+\mathrm{Zn}$ cells by combinatorial effects of native RAR $\alpha$ and the induced nascent PMLRAR $\alpha$ (Fig. 2d). Intriguingly, although the binding capacities of RAR $\alpha$ and PML-RAR $\alpha$ were similar (Fig. 2b), extensive chromatin interactions detected in PR9+Zn cells were largely associated with PML-RAR $\alpha$ binding loci, particularly the PML-RAR $\alpha$-specific binding loci. Collectively, our observations imply a substantial impact from PML-RAR $\alpha$ to alter the topological architecture of the myeloid genome.

To investigate how PML-RAR $\alpha$ affects the myeloid genome, we aggregated the PMLRAR $\alpha$-associated chromatin interactions into PML-RAR $\alpha$ contact domains, similarly to what we did for CTCF domains (Fig. 2a). Intriguingly, when integrating the PML-RAR $\alpha$ complex domains into the CTCF-defined topological framework of the myeloid genome (Additional file 2: Figure S2a), we found that many (249) PML-RAR $\alpha$ chromatin domains extended across the boundaries of two adjacent CCDs and connected parts of them, resembling "stitches" weaving multiple CCDs together. These "stitch" PMLRAR $\alpha$ complex domains usually involved high levels of chromatin contacts 
(Additional file 2: Figure S2b) and were prevalently spread across the entire genome (Additional file 2: Figure S2c). The resulting "stitched CCD" by PML-RAR $\alpha$ exhibited extended domain coverage (Additional file 2: Figure S2d), and thus potentially had a global impact on the overall topological organization of the myeloid genome. Such impacts were particularly visible at the level of topological domains. For example, at a 2.17-Mb segment of chr20, the two adjacent but separated CCD with scattered RAR $\alpha$ binding and looping in PR9 cells were brought together by a PML-RAR $\alpha$ chromatin domain with extensive binding and looping as shown in PR9+Zn cells (Fig. 2e, f). This observation was further validated by a two-color DNA-FISH experiment, showing that the two separated CTCF domains in PR9 cells were in much closer contacts in PR9+Zn cells than in PR9 cells (Fig. 2g). An ensemble structure-based algorithm was applied to the chromatin interaction data derived from PR9 and PR9+Zn cells (Additional file 3: supplementary methods) and elucidated the topological structural changes resulting from the action of the induced PML-RAR $($ Fig. 2h). Another example of the topological changes in PR9 cells before and after the $\mathrm{ZnSO} 4$ induction of PML-RAR $\alpha$ was at a 3-Mb segment on chr18 (Additional file 2: Figure S2e-g). Taken together, our data demonstrated that the fusion oncoprotein PML-RAR $\alpha$ acts through extensive chromatin binding and looping genome-wide and results in strong ectopic chromatin interactions that extend across the boundaries of CTCF-defined chromatin architectures in normal myeloid cells, thus leading to the topological reorganization of the myeloid genome into aberrant configurations in APL cells.

\section{Alteration of gene expression by PML-RARa}

Subsequently, we systematically analyzed the RNAPII ChIA-PET data in PR9 and PR9+Zn cells in relation to PML-RAR $\alpha$-defined chromatin domains and found that large numbers of RNAPII-associated chromatin interaction sites (proximal or distal to TSS) were co-occupied by PML-RAR $\alpha$ in PR9+Zn cells (Additional file 2: Figure S3a), indicating that PML-RAR $\alpha$ may also directly interfere with the transcription programs in myeloid cells. We then quantified RNAPII occupancy at these sites in PR9 cells before and after $\mathrm{ZnSO} 4$ induction of PML-RAR $\alpha$, to assess the effects of PML-RAR $\alpha$ on RNAPII. While most of the loci showed insignificant changes after $4 \mathrm{~h}$ of $\mathrm{ZnSO} 4$ induction, we identified 871 (20\%) loci that exhibited a significant reduction of RNAPII binding intensity (Fig. 3a). As analysis controls, less than 10\% of the non-PML-RAR $\alpha$ sites, including the RAR $\alpha$ binding sites, showed changes in RNAPII occupancy, presumably due to systems noise. Therefore, our observation suggests that PML-RAR $\alpha$ might specifically target a subset of RNAPII interaction loci and induce functions that repress gene transcription.

Next, we focused on the genes $(n=267)$ that were associated with the reduced RNAPII occupancy due to co-occupancy by PML-RAR $\alpha$ and analyzed their transcription output using RNA-seq data over a time course during ZnSO4 induction of PML-RAR $\alpha$ in PR9+Zn cells. Remarkably, more than half $(n=146)$ of these genes exhibited a corresponding pattern of transcriptional reduction over the time course during $\mathrm{ZnSO} 4$ treatment (Fig. 3b). To test if the observed transcriptional repression was directly related to the induction of PML-RAR $\alpha$, we added all-trans retinoic acid (ATRA) to PR9+Zn cells in order to rescue the gene expression potentially hampered by the induced PML- 


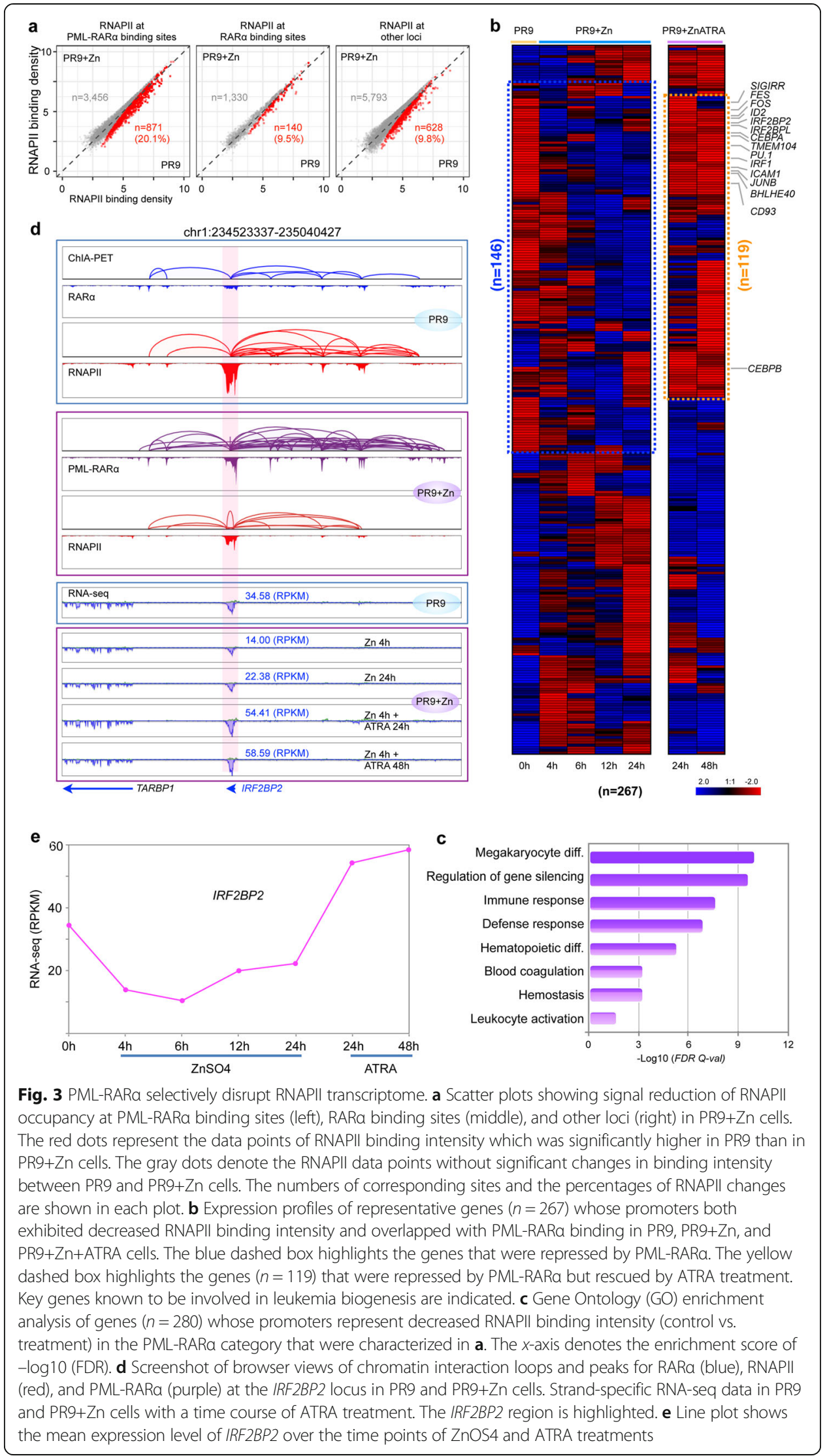


RAR $\alpha$. ATRA is an important drug in APL treatment. It causes degradation of the PML-RAR $\alpha$ fusion protein through the ubiquitin-proteosome and caspase systems [17, 18]. We therefore performed a "rescuing" experiment by adding ATRA to the PR9 cells that were under $\mathrm{ZnSO} 4$ induction of PML-RAR $\alpha$. Remarkably, in the "rescuing" experiments, most of the genes $(81.5 \% ; 119 / 146)$ were recovered by ATRA treatment, showing increased transcription (Fig. $3 \mathrm{~b}$ and Additional file 2: Figure S3b). Among these genes, many are known for their functions involved in myeloid cell differentiation, including transcription factors and cytokines, such as the previously reported $C E B P B$ [19], ID2 [20], and SPI1 [21] involved in megakaryocytic and granulocytic differentiation. Gene Ontology analysis to this set of genes showed that they are significantly enriched in biological processes associated with hemopoiesis, immune processes, myeloid cell activation, and differentiation (Fig. 3c), further validating that at least part of the functions of PML-RAR $\alpha$ is to act via repressing the transcription of genes involved in myeloid cell differentiation during APL pathogenesis.

As mentioned in Fig. 1e, the abundant RNAPII bindings and looping at the CEBPB promoter and its enhancer sites observed in PR9 cells were repressed by the induced PML-RAR $\alpha$ in PR9+Zn cells while the CTCF-mediated chromatin folding structures unchanged, exemplifying a profound repressive function to transcription by PMLRAR $\alpha$. Similarly, at the IRF2BP2 locus, there was modest RAR $\alpha$ ChIA-PET data and strong RNAPII-associated chromatin interactions between the IRF2BP2 promoter and multiple enhancers detected in PR9 cells. However, after induction by $\mathrm{ZnSO} 4$, robust PML-RAR $\alpha$ binding peaks and chromatin loops appeared, which directly overlapped with the RAR $\alpha$ and RNAPII associated chromatin sites as detected in PR9 cells. Coincidentally, the RNAPII signals were much reduced in PR9+Zn cells (Fig. 3d). Furthermore, the RNA-seq data in this region showed more than a 2-fold reduction of IRF2BP2 expression when PML-RAR $\alpha$ was induced in PR9+Zn cells and, strikingly, rebounded after the addition of ATRA (Fig. 3d, e). Together, the high degree of correlation between the repression by $\mathrm{ZnSO} 4$ induction for PML-RAR $\alpha$ expression and the liberation by ATRA treatment for PML-RAR $\alpha$ degradation convincingly suggests that this set of genes may be the direct targets of PML-RAR $\alpha$ for transcriptional repression in APL cells. It may also suggest mechanistically that PML-RAR $\alpha$ forcefully compress the chromatin topological structure around myeloid-specific transcriptional cassette through its extensive chromatin binding and looping, and thus limit the access for transcription machinery.

\section{Interference with transcription factor binding at enhancer sites by PML-RARa}

We reasoned that the potential specificity of PML-RAR $\alpha$ targeting a subset of actively transcribed genes in myeloid cells might be through interference with specific transcription factors (TFs). It is widely known that TFs can facilitate the physical chromatin contacts between promoters and distal regulatory elements by looping the intervening DNA between them [22, 23]. Specifically, PU.1 (also known as SPI1), known as a lymphoid-specific transcription activator, has been suggested to be associated with PML-RAR $\alpha$ [8]. To identify specific TFs involved at the PML-RAR $\alpha$ chromatin interaction sites, we performed TF motif analysis (Additional file 3: supplementary methods) and identified seven protein factors that were significantly enriched at PML-RAR $\alpha$ 
binding sites (Additional file 2: Figure S4a), including three TFs-PU.1, CEBPB, and IRF1 (Fig. 4a) - that are the most relevant and specific TFs in myeloid cells [8]. To further characterize these TFs, we performed ChIP-seq experiments and generated genome-wide binding profiles for PU.1, CEBPB, and IRF1 in PR9 and PR9+Zn cells, along with ChIP-seq of H3K9K14ac and P300 for promoters and enhancers. Interestingly, more than half of the TF binding sites found in PR9 cells were no longer present, or the binding signal intensities were significantly reduced, after PML-RAR $\alpha$ induction in PR9+Zn cells (Fig. 4b). It is noteworthy that the binding profiles of these TFs were highly correlated with transcriptionally active marks H3K9K14ac and P300 for promoters and enhancers, and RNAPII-associated chromatin interactions, higher in PR9 control cells (PR9) but lower in the cells under $\mathrm{ZnSO} 4$ induction of PML-RAR $\alpha$ (PR9+Zn). For example, at the PU.1 locus, PML-RAR $\alpha$ bound specifically at the PU.1 promoter site and interacted with a number of enhancers as indicated by H3K9K14ac and P300 binding profiles. In particular, at the enhancer sites, the occupancy by the three TFs (PU.1, CEBPB, and IRF1) was notably abolished or reduced in intensity, whereas the binding peaks for H3K9K14ac and P300 at the enhancers were also either decreased in signal intensity or abolished (Fig. 4c, left). The same observations were also exemplified at the CEBPB (Fig. 4c, right) and IRF1 loci (Additional file 2: Figure S4b).

Taken together, our results indicate that PML-RAR $\alpha$ directly interacts with specific chromatin loci and disrupts the transcription of specific TFs. More importantly, the reduced TF activities likely further dysregulate the transcription programs of downstream target genes that are important for normal myeloid cell differentiation.

\section{Disruption of super-enhancers by PML-RARa}

The experiments above showing that PML-RAR $\alpha$ disrupts the cobinding of multiple cofactors at RAR $\alpha$ sites suggest that PML-RAR $\alpha$ would perturb the superenhancer function. Super-enhancers (SEs), as a subset of regulatory elements, have been proposed to facilitate interactions between enhancers and promoters primarily associated with highly transcribed genes controlling cell identity and characteristically engaged multiple TFs at high intensity [24, 25]. Previous studies have shown that SEs are critical in establishing and maintaining cell-specific transcriptional regulation of gene expression as well as fine-tuning of the expression of many oncogenes $[26,27]$. Given that the induced PML-RAR $\alpha$ prominently targeted at genomic regions with high levels of H3K9K14ac modification (Fig. 5a), we used the H3K9K14ac ChIP-seq data to catalog SEs using the ROSE algorithm [26, 27] in PR9 and PR9+Zn cells (Fig. 5b). In total, we identified 521 SEs overlapped with PML-RAR $\alpha$ binding sites in PR9+Zn cells (Additional file 2: Figure S5a), implying that PML-RAR $\alpha$ may broadly interfere with the functions of SEs. Remarkably, of the 480 SEs identified in PR9 cells, more than half $(n=247)$ lost their SE characteristics (H3K9K14ac signals) after $\mathrm{Zn}$ induction for PML-RAR $\alpha$ PR9+Zn cells (Fig. 5c). It is observed that the RNAPII ChIA-PET data intensities (peaks and loops) associated with these SEs in PR9 cells were significantly decreased in PR9+Zn cells, in contrast to the induction of PML-RAR $\alpha$ and associated binding peaks and loops in PR9+Zn cells (Fig. 5d). 


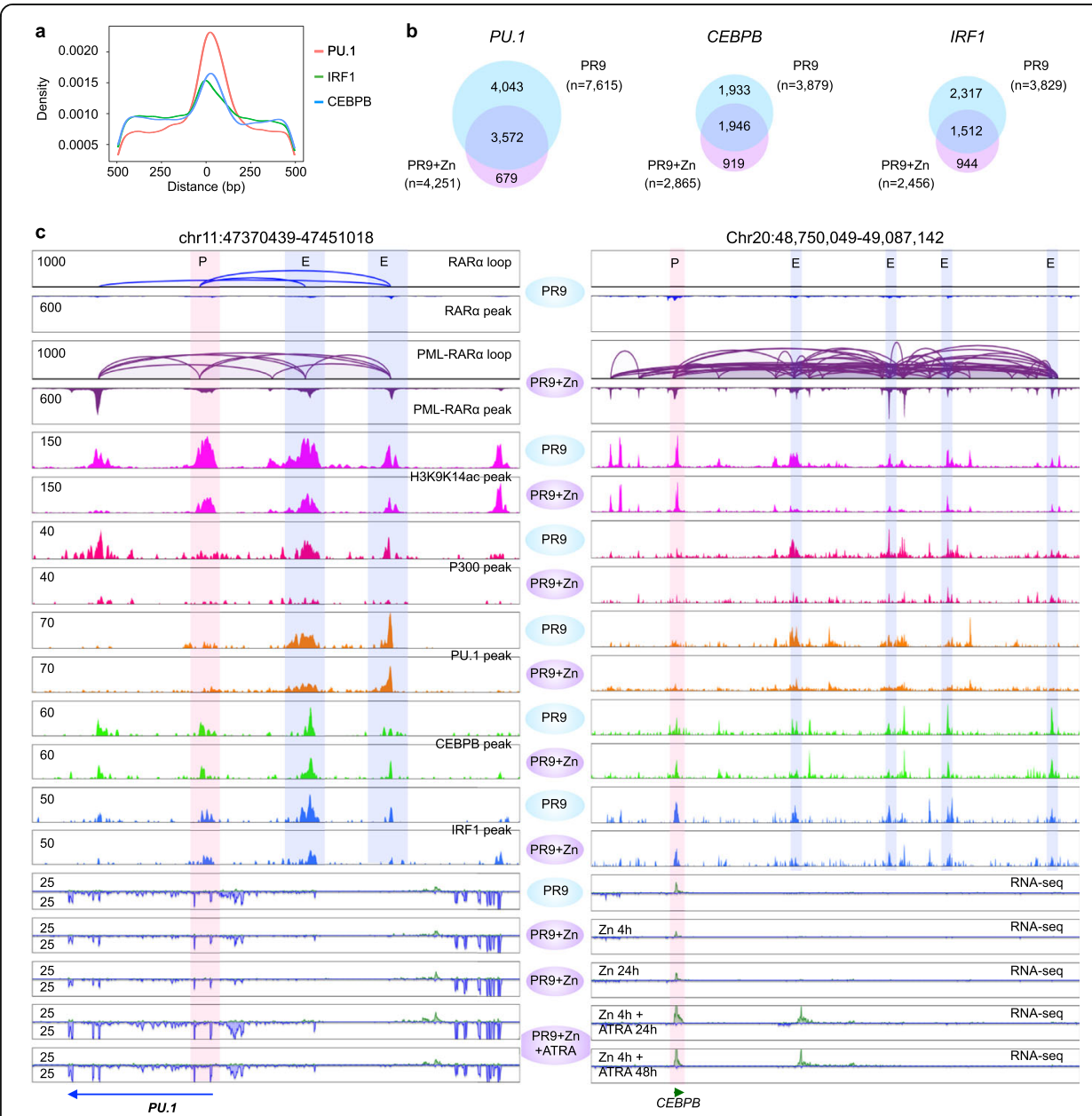

Fig. 4 PML-RARa interrupted the transcription activity of key transcription factors. a Motif enrichments of hematopoietic transcription factor at PML-RARa binding sites. $\mathbf{b}$ Venn diagrams of the overlapped binding sites by three TFs (PU.1, CEBPB, and IRF1) in PR9 and PR9+Zn cells. c Two examples (left, on chr11; right, chr20) showing PML-RARa binding and looping, where the occupancy by H3K9K14ac (pink), P300 (red), PU.1 (orange), CEBPB (green), and IRF1 (blue) in PR9 cells was notably reduced in PR9+Zn cells. The promoter site is highlighted in light red, and the enhancer sites are highlighted in light blue

Based on the connectivity of RNAPII ChIA-PET data, we detected 282 genes that were linked to the PML-RAR $\alpha$-affected SEs $(n=247)$. Subsequent GO analysis of this gene set identified 123 genes that were highly associated with functions in myeloid cell differentiation and positive regulation of myeloid leukocyte differentiation and myeloid cell homeostasis (Additional file 2: Figure S5b). Many of these 123 genes, including FOS, IRF2BP2, ID2, IRF1, IRF2BPL, and BHLHE40, were highly expressed in PR9 cells but repressed under $\mathrm{ZnSO} 4$ treatment conditions (Additional file 2: Figure S5c), as highlighted in Fig. 5b. In contrast, although 215 genes were found associated with the SEs $(n=233)$ that were not affected by PML-RAR $\alpha$, most of those genes were not associated with myeloid-specific functions (Additional file 2: Figure S5b).

At the IRF2BPL locus, only base-level RAR $\alpha$ signals but substantial RNAPII peaks and loops connect the IRF2BPL promoter and enhancers in PR9 cells (Fig. 5e). However, following $\mathrm{ZnSO} 4$ induction, strong PML-RAR $\alpha$ binding peaks and loops were observed in PR9+Zn cells overlapping directly with the RNAPII binding site loops 

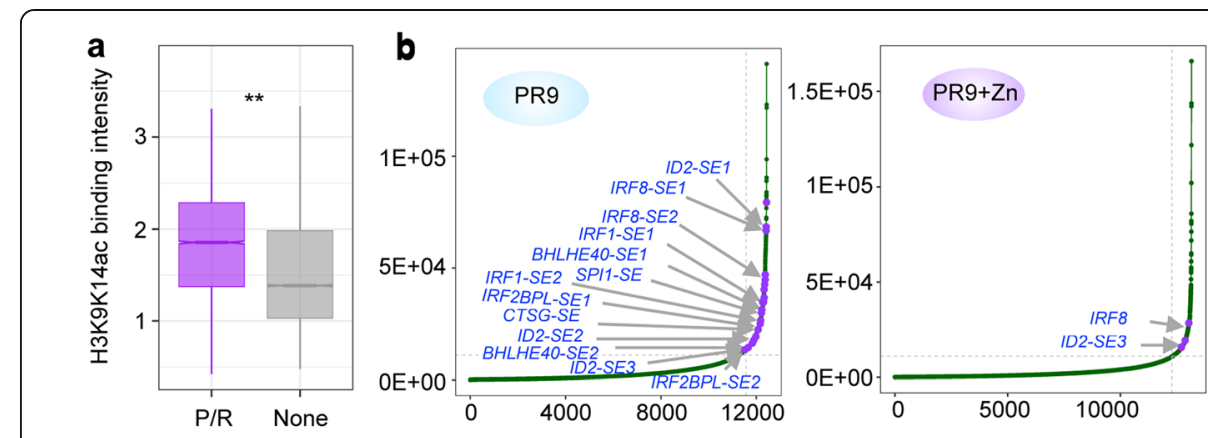

C

d
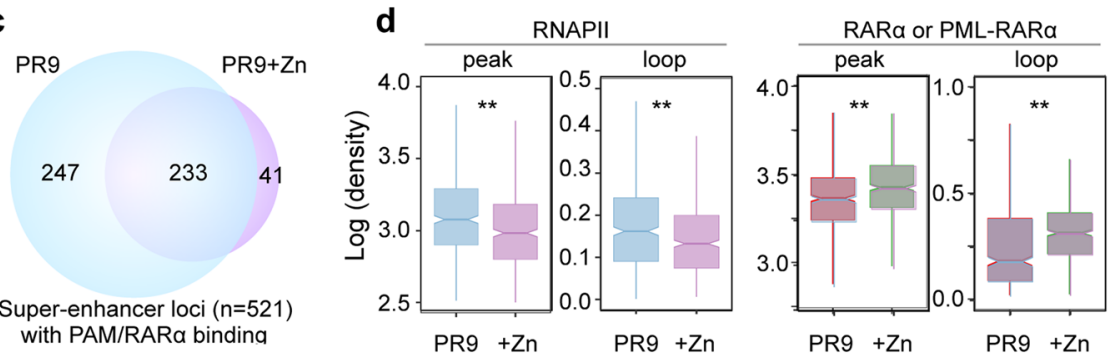

e

Chr14:77359915-77553224
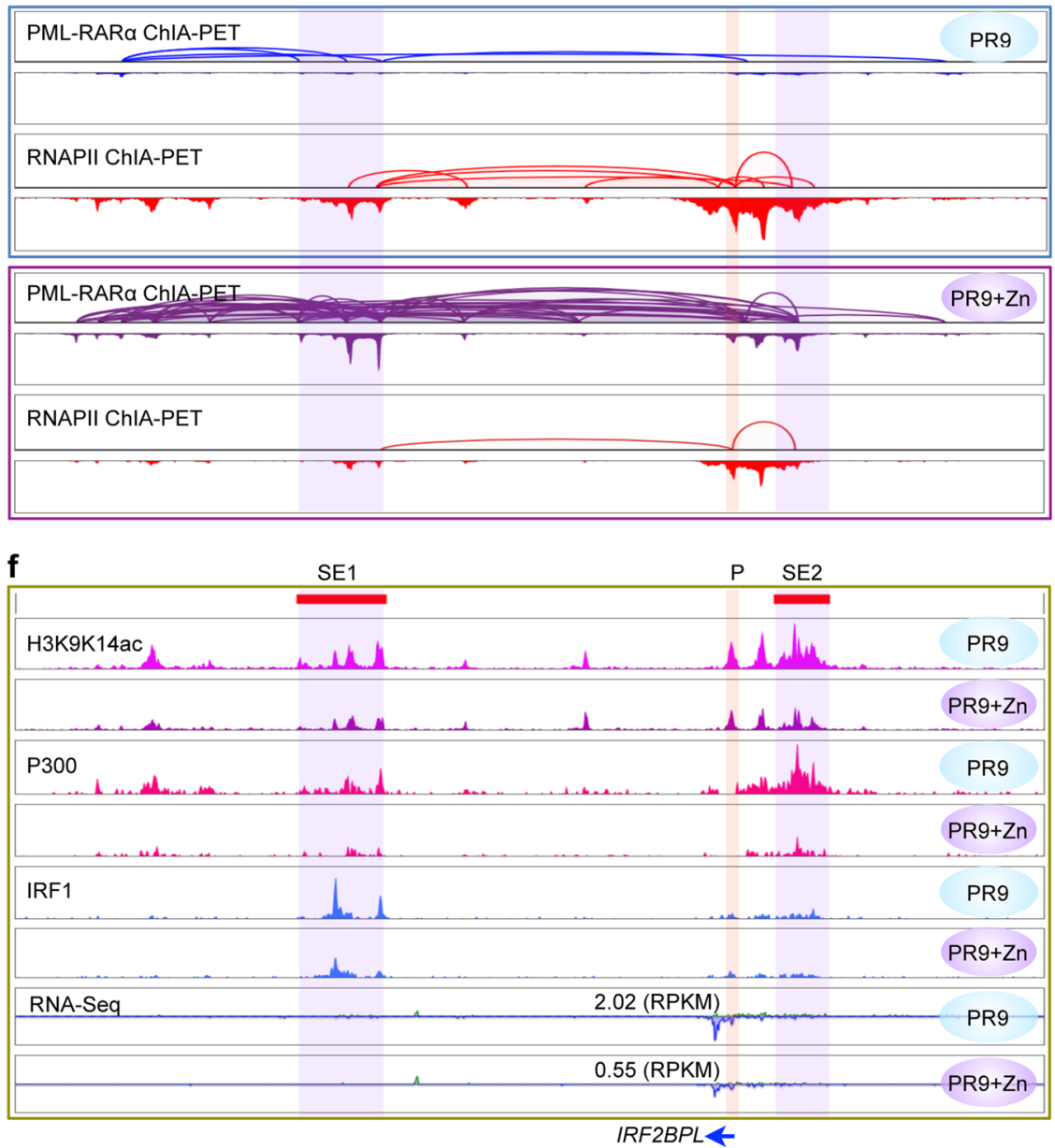

Fig. 5 (See legend on next page.) 
(See figure on previous page.)

Fig. 5 Super-enhancers affected by PML-RARa. a Boxplots of H3K9K14ac ChIP-seq intensity at the PMLRARa (P/R, purple) interaction binding sites or not as identified in PR9+Zn cells. The control (gray) represents H3K9K14ac signals at non-PML-RARa anchor loci (None). Paired $t$ test was used to test the difference. ${ }^{* *} p<0.001$. b Distribution plots of H3K9K14ac ChIP-seq signals and the super-enhancers (SEs) identified in PR9 and PR9+Zn cells. SEs were ranked by increasing H3K9K14ac signals. SEs associated with genes critical in myeloid differentiation are highlighted in red. c Venn diagram of the numbers of unique and common SEs in PR9- and ZnSO4-treated PR9 cells based on differential analysis of H3K9K14ac signals. d Boxplots for normalized data signal intensity of RNAPII binding and loops at SE sites in PR9 and PR9+Zn ( $+\mathrm{Zn})$ cells (left), and the RARa binding and looping in PR9 cells and PML-RARa binding and looping in PR9 $+Z n(+Z n)$ cells at SE sites (right). ${ }^{*} p<0.001$, by Kolmogorov-Smirnov test. e An example of chromatin interactions at the IRF2BPL locus identified by ChIA-PET of RARa (blue) and RNAPII (red) in PR9 cells, and PML-RARa (purple) and RNAPII (red) in PR9+Zn cells. Each ChIA-PET data are shown in tracks of loops (up) and peaks (below). f At the same location as in e, two SEs (highlighted) were identified with clusters of multiple H3K9K14ac peaks in PR9 cells. The H3K9K14ac peak signals were notably reduced in PR9+Zn cells. Similarly, the ChIP-seq signals for P300 and IRF1obserevd in PR9 cells were also reduced in PR9+Zn cells. Also, the expression of IRF2BPL as measured by RNA-seq data (RPKM) in PR9 cells was reduced by more than twofold in PR9+Zn cells

observed in PR9 cells. Consequently, the RNAPII signals in PR9+Zn cells were significantly diminished compared to the RNAPII signals in PR9 cells (Fig. 5e). Evidently, the H3K9K14ac peak profile in this region called for two SEs (Fig. 5f) interconnecting with the IRF2BPL promoter by a substantial number of RNAPII loops in PR9 cells. Notably, the SE signals were substantially reduced in PR9+Zn cells, presumably by the PMLRAR $\alpha$ effects. Similarly, P300, another enhancer mark, showed the same pattern, with strong signals in PR9 cells, but diminished signals in PR9+Zn cells (Fig. 5f). Interestingly, the occupancy of IRF1 (a TF important for hematopoiesis) at the SE1 site was also much reduced in PR9+Zn cells. Correspondingly, the IRF2BPL expression was 2.5fold downregulated in PR9+Zn cells (Fig. 5f). Another example is at the FOS locus (Additional file 2: Figure S5d).

Altogether, the above results demonstrated that PML-RAR $\alpha$ may directly intrude super-enhancers, and the loss of properties of SEs may contribute to the disruption of RNAPII-mediated SE-to-promoter connectivity, consequently dysregulating gene transcription and altering the cell lineage controls during APL genesis.

\section{Native PML-RARa in patient-derived APL cell functions similarly to the inducible PML-} RARa

To validate the above findings in the PR9 cellular system, we analyzed NB4 cells, a cell line derived from an APL patient harboring the $\mathrm{t}(15,17)$ translocation and expressing a native PML-RAR $\alpha$ fusion protein [28]. Therefore, the cellular state of NB4 (with native PML-RAR $\alpha$ ) would be comparable to PR9+Zn cells (with induced PML-RAR $\alpha$ ). We also treated NB4 cells with ATRA (NB4+ATRA) to deplete the native PML-RAR $\alpha$. These NB4+ATRA cells (with PML-RAR $\alpha$ depleted) thus match with the PR9 cells (no PML-RAR $\alpha$ ). We reasoned that, with these parallels between the NB4 and the PR9 inducible systems, a comparative analysis of the two systems would yield insights into the property and function differences between the inducible and native PML-RAR $\alpha$ (Fig. 6a). First, we performed RNA-seq for gene expression analysis in the pairs of NB4 vs. PR9+Zn cells and the NB4+ATRA vs. PR9 cells. The overall gene expression profiles between the two pairs exhibited high correlations (Fig. $6 \mathrm{~b}$ and Additional file 2: Figure 

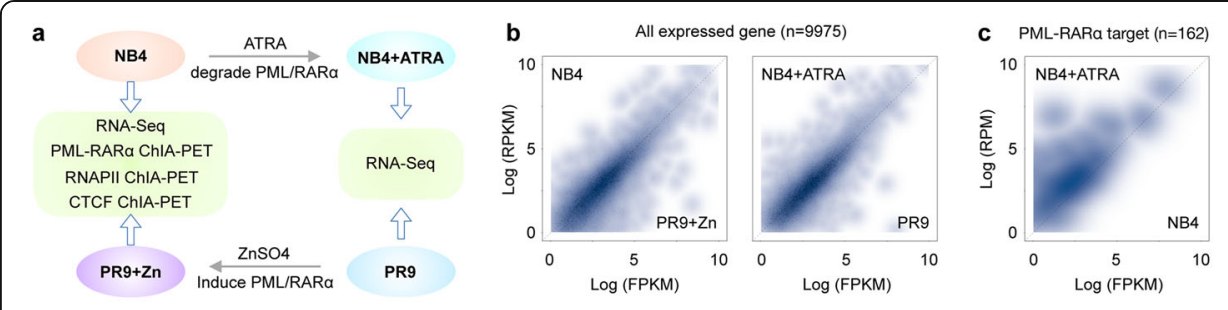

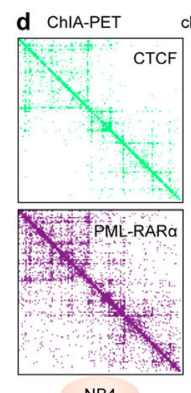

chr9:131,848,507-133,096,052 (1.24 Mb)

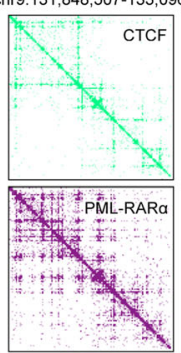

PR9+Zn

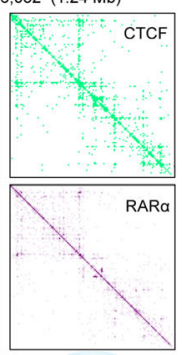

PR9

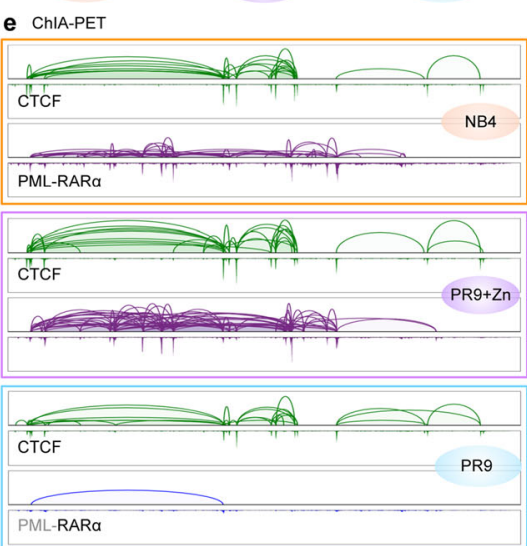

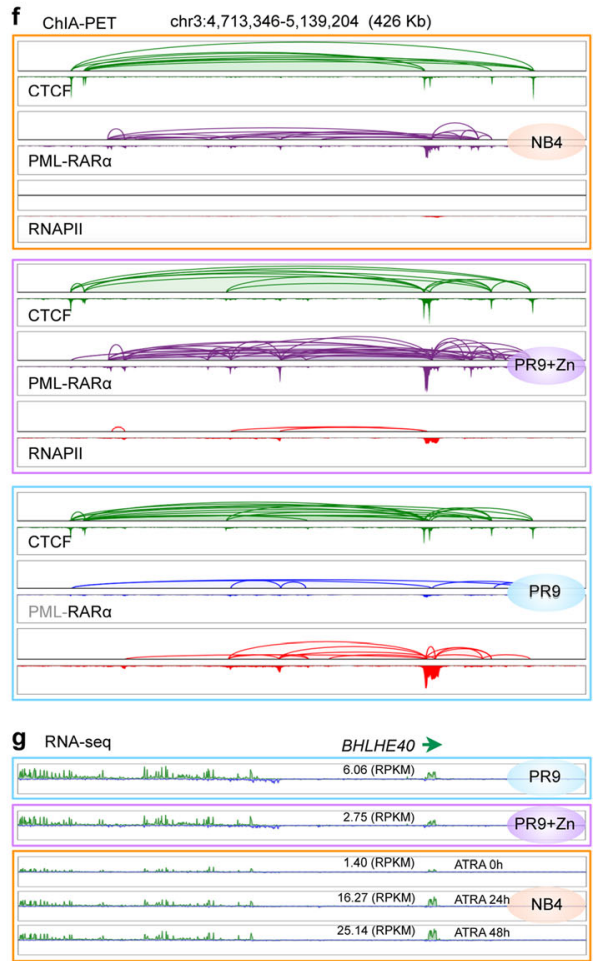

Fig. 6 Native PML-RARa in patient-derived APL cells behaved the same as induced PML-RARa. a Schematic design for comparison of transcription (RNA-seq) and 3D genome organization (ChIA-PET of PML-RARa, RNAPII, and CTCF) between patient-derived APL cells (NB4, with native PML-RARa) and PR9 cells by ZnSO4 induction (PR9+Zn, with induced PML-RARa), as well as for comparison of transcription (RNA-seq) between NB4 cells under ATRA treatment (NB4+ATRA, with native PML-RARa depleted) and PR9 cells without PMLRARa. $\mathbf{b}$ Contour plots for the correlation of gene expression (RPKM) between NB4 vs. PR9+Zn cells (left) and NB4+ATRA vs. PR9 cells (right). c Contour plots for the correlation of gene expression (RPKM) of the 146 PML-RARa target genes between NB4 and NB4+ATRA cells. $\mathbf{d}$ Integrated 2D contact maps of PML-RARa (up, purple) and CTCF (low, green) ChIA-PET data in NB4 (left), PR9+Zn (middle), and PR9 (right) cells. e A screenshot of browser view for chromatin loops and peaks by CTCF (green) and PML-RARa (purple) showing a high similarity between NB4 (top) and PR9+Zn (middle) cells. Chromatin loops and peaks by CTCF (green) and RARa (blue) in PR9 cells are included as a reference for normal myeloid cells. $\mathbf{f}$ An example for comparison at the BHLHE4O locus of chromatin loops peaks by CTCF (green), PML-RARa (purple) or RARa (blue), and RNAPII (red) in cells of NB4 (orange box), PR9+Zn (purple box), and PR9 (blue box) cells. It indicated that the chromatin structures mediated by CTCF, and PML-RARa, and RNAPII in NB4 cells and PR9+Zn cells were highly comparable. When compared to the data in PR9 cells, both NB4 and PR9+Zn cells exhibited high levels of PML-RARa chromatin interactions, but basal levels of RNAPII occupancy. $\mathbf{g}$ At the same BHLHE4O locus, the expression (RPKM) of gene BHLHE4O as measured in PR9 were significantly reduced in PR9+Zn and NB4 cells but recovered in NB4 cells after ATRA treatments

S6a), indicating that the cellular systems of NB4 and PR9 were very comparable. However, when comparing the NB4 and NB4+ATRA cells, we observed that significant numbers of genes were upregulated, including many myeloid-specific genes (Additional file 2: Figure S6b). Sperifically to the set of genes $(n=146)$ targeted by PML- 
RAR $\alpha$ (Fig. 3b), all of them were upregulated in NB4+ATRA cells (Fig. 6c), suggesting that native PML-RAR $\alpha$ had similar effects to myeloid-specific genes as in the PR9 cellular system by the induced PML-RAR $\alpha$ fusion protein.

Next, we performed ChIA-PET analyses for protein factors CTCF, PML-RAR $\alpha$, and RNAPII in NB4 cells and then compared with the same datasets derived from PR9+Zn (Fig. 6a; Fig. 1b-d). Similarly, the RNAPII and PML-RAR $\alpha$ binding peak profiles between NB4 and PR9+Zn cells were also highly correlated (Additional file 2: Figure S6b). We further analyzed the chromatin contacts of the ChIA-PET data. The 2D contact profiles of the PML-RAR $\alpha$ ChIA-PET data obtained in NB4 cells appeared to be very similar to the PML-RAR $\alpha$ data in PR9+Zn cells, and obviously different from the RAR $\alpha$ (no PML) data in PR9 cells (Fig. 6d), clearly indicating that the native PMLRAR $\alpha$ in NB4 cells behaved similarly to the induced PML-RAR $\alpha$ in PR9+Zn cells. As a reference, the CTCF-mediated chromatin contacts in NB4, PR9+Zn, and PR9 cells were highly comparable, as expected. More specifically, the CTCF loops and peaks were highly consistent in the three samples, and the PML-RAR $\alpha$ loops and peaks were also consistent in NB4 and PR9+Zn cells, but not the same in PR9 cells, where there were no PML-RAR $\alpha$ data except the data derived from RAR $\alpha$ (Fig. 6e). Collectively, these observations suggested that the behavior of native PML-RAR $\alpha$ in genome topological organization in NB4 cells was similar to that of the induced PML-RAR $\alpha$ in PR9+Zn cells.

Furthermore, we observed that PML-RAR $\alpha$ in NB4 cells also strongly inhibits RNAPII occupancy and transcriptional chromatin interactions at many myeloid-specific gene loci in PR9 cells (Additional file 2: Figure S6a). For instance, at the BHLHE40 locus in PR9 cells (Fig. 6f), RNAPII showed abundant occupancy at the gene promoter and mediated extensive chromatin loops to enhancers. However, at the same locus in PR9+Zn and NB4 cells, strong PML-RAR $\alpha$ binding and looping were observed, and the RNAPII signals were diminished (Fig. 6f). To further investigate whether the native PML-RAR $\alpha$ in NB4 cells affects the gene expression of myeloid-specific genes, as we showed in PR9 and PR9+Zn cells, we added ATRA to NB4 cells to deplete the native PML-RAR $\alpha$ and then measured the transcripts by RNA-seq analysis. Differential expression analysis showed that many myeloid-specific genes expressed at high levels in PR9 cells (HCK, BHLHE40, CEBPB, IRF1, etc.) were repressed in NB4 cells and were reactivated after $24 \mathrm{~h}$ and $48 \mathrm{~h}$ of ATRA treatments (Additional file 2: Figure S6a). For example, the normal expression of BHLHE4O in PR9 cells was at a modest level (6.06 RPKM) and was repressed more than twofold (2.73 RPKM) after $4 \mathrm{~h}$ of $\mathrm{ZnSO} 4$ induction of PML-RAR $\alpha$ in PR9+Zn cells. At the same locus in NB4 cells, BHLHE40 was repressed. However, after ATRA treatment, the expression of this gene increased more than tenfold (Fig. 6g). Another prominent example is at the FOS locus (Additional file 2: Figure S6c). Together, these results further suggested that our observations for PML-RAR $\alpha$ in the PR9 inducible system faithfully reflected the native PML-RAR $\alpha$ functions for chromosomal reorganization and transcriptional repression in patient-derived APL cells.

\section{Discussion}

In this study, we comprehensively mapped the 3D genome organizations and epigenomic features of normal myeloid cells and APL cells using integrative approaches 
including ChIA-PET for chromatin topology, ChIP-seq for epigenomic state, and RNAseq for transcriptional output, to analyze the effects of the oncogenic fusion protein PML-RAR $\alpha$ on the myeloid genomes. Significantly, we employed an inducible myeloid system, in which the expression of the PML-RAR $\alpha$ protein is precisely controlled by $\mathrm{ZnSO} 4$ induction. With this system, we investigated the dynamic changes in chromatin topology triggered by nascent PML-RAR $\alpha$ in the initial transformation stage, beginning at the normal myeloid state in leukemogenesis. We also analyzed the patient-derived APL cells harboring native PML-RAR $\alpha$ to validate our observations in the inducible myeloid system.

Collectively, in this study, we provided convincing data demonstrating that the PMLRAR $\alpha$ proteins are aggressively involved in extensive chromatin interactions genomewide in a specific manner. Although the DNA-binding properties of PML-RAR $\alpha$ are derived from RAR $\alpha$, more than two thirds (2/3) of the PML-RAR $\alpha$ binding loci did not overlap with RAR $\alpha$ binding sites, indicating that this fusion protein acquired novel chromatin interacting capacities. Intriguingly, our data indicated that PML-RAR $\alpha$ did not directly interfere with CTCF binding and chromatin looping, but rather that many of the PML-RAR $\alpha$-mediated chromatin loops overlapped the boundaries of CTCFdefined topological structures, and acted as a "stitch" or "staple" to interconnect separate chromatin topological structures into much larger domains with more condensed configuration, thereby reshaping the chromatin topology in normal myeloid cells leading to leukemogenesis.

Importantly, we also demonstrated that PML-RAR $\alpha$ specifically intrudes upon RNAPII-associated chromatin interaction domains of active genes in myeloid cells interrupting or competing for the binding of myeloid-specific TFs such as PU.1, IRF1, and CEBPB at enhancers and super-enhancers as demarcated by H3K9K14ac and P300 in open chromatin loci. The extensive chromatin binding and looping by PML-RAR $\alpha$ could substantially compress the chromatin topological structures around myeloidspecific transcriptional cassettes, thus leading to transcriptional repression of genes that are critical for myeloid differentiation and maturation. Perturbation experiments via induction (by ZnSO4) and depletion (by ATRA) of in vivo PML-RAR $\alpha$ in PR9 cells to repress and to rescue the normal myeloid differentiation expression cassette further validated the specificity of PML-RAR $\alpha$-targeted genes. Additional perturbation experiments with native PML-RAR $\alpha$ in patient-derived NB4 cells by ATRA treatment provided further evidence verifying PML-RAR $\alpha$ 's target specificity in gene transcription repression.

Taken together, our findings comprised a comprehensive view of the involvement of PML-RAR $\alpha$ in chromatin topology during the early transformation process of PML-RAR $\alpha$-triggered APL genesis. Mechanistically, we posit that PML-RAR $\alpha$ overrides the normal regulatory control of myeloid differentiation by reshaping the higher-order chromatin topology and compressing the transcriptional chromatin architectures. Therefore, the compressed chromatin domains would have reduced open access by specific TFs and RNAPII, thus repress the transcription of genes critical to myeloid differentiation, and ultimately lead to leukemogenesis. In sum, our results provide novel topological insights for the roles of PML-RAR $\alpha$ in transforming myeloid cells into leukemia cells, likely a general mechanism for oncogenic fusion proteins in cancers. 


\section{Methods}

\section{Cell lines and culture conditions}

PR9 (U937-PR9) cell line is a PML-RAR $\alpha$-inducible model constructed from U937, a normal myeloid precursor cell line without the $t(15 ; 17)$ translocation but expressing many myeloid-specific transcription factors important in myeloid development, including PU.1. To avoid the potential bias of clonal variations in culture, a single-cell subclone was selected. NB4 is a patient-derived APL cell line, carrying the $t(15 ; 17)$ translocation and expressing the PML-RAR $\alpha$ fusion protein. Both PR9 and NB4 cells were cultured in RPMI 1640 (Thermo Fisher, A10491), supplemented with $10 \%$ fetal bovine serum (Thermo Fisher, 10082147). These cells were cultured at $37^{\circ} \mathrm{C}, 5 \% \mathrm{CO}_{2}$, and ambient oxygen levels.

ZnSO4 (Sigma, Z0251) was dissolved in sterile water as a stock solution at $100 \mathrm{mM}$. Induction for PML-RAR $\alpha$ by ZnSO4 in PR9 cells was $100 \mu \mathrm{M} \mathrm{ZnSO} 4$ for $4 \mathrm{~h}$.

ATRA (Sigma, R2625) was dissolved in ethanol as a stock solution at $1 \mathrm{mM}$. ATRA treatment in NB4 cells was $10^{-6}$ M ATRA for 24 or $48 \mathrm{~h}$.

\section{ChIA-PET library preparation}

ChIA-PET libraries with an antibody against PML, RAR $\alpha$, RNAPII, and CTCF were constructed using about $10^{8}$ input cells from PR9, PR9+Zn, and NB4 cell cultures, following the ChIA-PET protocol $[29,30]$. The ChIA-PET libraries were sequenced by paired-end reads using Illumina instruments.

\section{ChIP-seq}

In this study, we generated ChIP-seq data from PR9 and PR9+Zn cells for TFs of P300, PU.1, CEBPB, and IRF1, using the following antibodies: anti-P300 (Abcam, ab14984), anti-PU.1 (Santa Cruz, sc-352X), anti-IRF1 antibody (Santa Cruz, sc-497x), and antiCEBPB antibody (Santa Cruz, sc-150x), and followed standard ChIP-seq protocol [8].

\section{RNA isolation and RNA-seq library preparation}

Total RNA was extracted with RNeasy mini kit (Qiagen, 74106) from the following cells: PR9 cells, PR9 cells treated with ZnSO4 (final concentration is $100 \mu \mathrm{M}$ ) at different time points $(4 \mathrm{~h}, 6 \mathrm{~h}, 12 \mathrm{~h}, 24 \mathrm{~h})$, PR9 cells pre-incubated with $\mathrm{ZnSO} 4$ for $4 \mathrm{~h}$ and then treated with ATRA (final concentration is $1 \mu \mathrm{M}$ ) for another 24 or $48 \mathrm{~h}$, and NB4 cells and NB4 cells treated with ATRA (final concentration is $1 \mu \mathrm{M}$ ) for 24 and $48 \mathrm{~h}$. Prior to RNA-seq library preparations, rRNAs were depleted using Ribo-Zero rRNA removal kits (Illumina Inc., MRZH11124) from total RNA. Then, RNA libraries were prepared by the ScriptSeq RNA-seq library preparation kit (Illumina Inc., SSV21124). The RNA-seq libraries were sequenced using the NextSeq 500 platform for paired-end sequencing.

\section{D DNA-FISH}

The 3D DNA-FISH was performed with custom-synthesized oligonucleotides probes (MYcroarray) according to candidate genome loci (probe A-chr20: 31,261,904-31,361, 904; probe B-chr20: 30,141,728-30,241,728) [16]. PR9 cells and PR9 cells treated with $\mathrm{ZnSO} 4$ (final concentration is $100 \mu \mathrm{M}$ ) for $4 \mathrm{~h}$ were spun down onto a coverslip slide 
coating with poly-lysine for $20 \mathrm{~min}$; then, the slides were washed with PBS for 3 times and air-dried. The cells were fixed in methanol/acetic acid solution (3:1) for $5 \mathrm{~min}$ at $4^{\circ}$, air-dried, and washed with PBS for $5 \mathrm{~min}$. The cells were dehydration through an ethanol series $(70 \%, 90 \%, 100 \%)$ and air-drying. Then, the cells were permeabilized with 0.5\% Triton X-100 in PBS on ice for 5 min and washed with PBS for 5 min. Customized FISH probe (MYcroarray) was warmed and mixed with hybridization buffer well. The cells and the probe mix were simultaneously subjected to DNA denaturation at $80^{\circ} \mathrm{C}$ for $5 \mathrm{~min}$. The hybridization was performed at $37^{\circ} \mathrm{C}$ in the humid dark chamber overnight. After coverslip removal, one wash for $10 \mathrm{~min}$ at RT with $2 \times \mathrm{SSC} / 50 \%$ deionized formamide, $\mathrm{pH} 7.0$, followed by one wash for $10 \mathrm{~min}$ at RT with $2 \times \mathrm{SSC}$ and two washes for $10 \mathrm{~min}$ at $55^{\circ} \mathrm{C}$ with $0.2 \times \mathrm{SSC}$ were performed. Then, cells on the slides were incubated with ProLong ${ }^{\text {Tx }}$ Gold Antifade Mountant with DAPI (Thermo Fisher, 36931) in PBS buffer for $5 \mathrm{~min}$ and examined under the Leica SP8 confocal microscope. The distances between the probe pair were measure in 3D with IMARIS 9 software.

\section{Supplementary information}

Supplementary information accompanies this paper at https://doi.org/10.1186/s13059-020-02030-2.

Additional file 1: Supplementary tables. Table S1. Dataset used in this study. Table S2. Reagents used in this study. Table S3. Software and algorithms used in this study.

Additional file 2: Supplementary figures. Figure S1. Comparison of CTCF and RNAPII binding and looping in PR9 and PR9+Zn cells. Figure S2. PML-RARa-mediated chromatin interaction domain and impacts on the myeloid genome. Figure S3. Transcription repression of myeloid specific genes by PML-RARa. Figure S4. Further details of motif analysis around PML-RARa binding sites. Figure S5. Super-enhancers of myeloid specific genes affected by PML-RARa. Figure S6. Additional examples of PML-RARa in NB4 cell.

Additional file 3. Supplementary methods. 1. ChIA-PET data processing and clustering of interaction PETs. 2. Comparison of ChIA-PET data for calling of binding peaks, loops, and chromatin domains. 3. Identification and classification of RARa and PML-RARa binding sites. 4. Identification and characterization of PML-RARa-mediated chromatin interactions. 5. Visualization of 2D contact map and BASIC browser. 6. 3D chromatin structure modeling, measurement of 3D structure condensation and visualization. 7. Identification of binding motifs at PML-RARa peak regions. 8. Comparison of RNAPII-mediated chromatin interactions between control and treatment condition. 9. RNA-Seq and differential gene expression analysis. 10. ChIP-Seq analysis. 11. Identification and characterization of superenhancers. 12. Quantification and statistical analysis methods.

Additional file 4: Table S4. Differential expression of genes (267) affected by PML-RARa in PR9 cells.

Additional file 5. Review history.

\section{Acknowledgements}

The authors thank Dr. Oscar Junhong Luo and Dr. Guliang Li for the initial data analysis and Dr. Roel Verhaak for the valuable comments on the manuscript.

Peer review information

Yixin Yao was the primary editor of this article and managed its editorial process and peer review in collaboration with the rest of the editorial team.

Review history

The review history is available as Additional file 5.

\section{Authors' contributions}

YR conceptualized and supervised this study. PW designed the experiments and generated all genomic data with the assistance from XR and MZ on library construction. ZT, BL, and SZT analyzed the data. JJZ and LC performed the 3D DNA-FISH experiments and data analysis. PS and DP performed the simulation and visualization of the 3D chromatin folding models. PW, ZT, and YR interpreted the results and wrote the manuscript with inputs from ETL and C-LW. The authors read and approved the final manuscript.

\section{Funding}

YR is supported by NIH UM1 (HG009409, ENCODE), U54 (DK107967, 4DN), HFSP (RGP0039/2017), and the Roux family endowment. ETL is supported by NCl grant P30CA034196. PW is supported by the Young Scientists Fund of the National Natural Science Foundation of China (Grant No: 31100942). DP and PS are also supported by the Polish National Science Centre (2014/15/B/ST6/05082; UMO-2013/09/B/NZ2/00121), National Leading Research Centre in Bialystok, and European Union under the European Social Fund. 


\section{Availability of data and materials}

Genome-wide sequencing raw reads and processed files have been deposited at GEO. The accession number for the ChIA-PET, ChIP-seq, and RNA-seq datasets for PR9 and NB4 cells reported in this paper is GEO: GSE137662 [31]. H3K9K14ac ChIP-seq data of PR9 cells were downloaded from the GEO database under the accession number of GSM468215. All datasets, materials, and softwares used in this study are listed in Additional file 1 Table S1, S2, and S3, respectively.

\section{Ethics approval and consent to participate}

Not applicable

\section{Competing interests}

The authors declare that they have no competing interests.

\section{Author details}

${ }^{1}$ The Jackson Laboratory for Genomic Medicine, 10 Discovery Drive, Farmington, CT 06030, USA. ${ }^{2}$ Present Address: Sun Yat-sen University, Guangzhou, Guangdong, China. ${ }^{3}$ Department of Genetics and Genome Sciences, University of Connecticut Health Center, 400 Farmington Avenue, Farmington, CT 06030, USA. ${ }^{4}$ Centre of New Technologies, University of Warsaw, Stefana Banacha 2c, 02-097 Warsaw, Poland.

Received: 26 February 2020 Accepted: 27 April 2020

Published online: 11 May 2020

\section{References}

1. Mitelman F, Johansson B, Mertens F. The impact of translocations and gene fusions on cancer causation. Nat Rev Cancer. 2007:7:233-45.

2. Rowley JD. Chromosome translocations: dangerous liaisons revisited. Nat Rev Cancer. 2001;1:245-50.

3. Goddard AD, Borrow J, Freemont PS, Solomon E. Characterization of a zinc finger gene disrupted by the t(15;17) in acute promyelocytic leukemia. Science. 1991;254:1371-4.

4. de Thé $H$, Chomienne $C$, Lanotte M, Degos L, Dejean A. The $t(15 ; 17)$ translocation of acute promyelocytic leukaemia fuses the retinoic acid receptor a gene to a novel transcribed locus. Nature. 1990;347:558-61.

5. Apfel CM, Kamber M, Klaus M, Mohr P, Keidel S, LeMotte PK. Enhancement of HL-60 differentiation by a new class of retinoids with selective activity on retinoid X receptor. J Biol Chem. 1995;270:30765-72.

6. Botling J, Castro DS, Oberg F, Nilsson K, Perlmann T. Retinoic acid receptor/retinoid X receptor heterodimers can be activated through both subunits providing a basis for synergistic transactivation and cellular differentiation. J Biol Chem. 1997;272:9443-9

7. Pandolfi PP. Oncogenes and tumor suppressors in the molecular pathogenesis of acute promyelocytic leukemia. Hum Mol Genet. 2001;10:769-75.

8. Wang K, Wang P, Shi J, Zhu X, He M, Jia X, et al. PML-RARalpha targets promoter regions containing PU.1 consensus and RARE half sites in acute promyelocytic leukemia. Cancer Cell. 2010;17:186-97.

9. Martens JHA, Brinkman AB, Simmer F, Francoijs K-J, Nebbioso A, Ferrara F, et al. PML-RARalpha/RXR alters the epigenetic landscape in acute promyelocytic leukemia. Cancer Cell. 2010;17:173-85.

10. Villa R, Pasini D, Gutierrez A, Morey L, Occhionorelli M, Viré E, et al. Role of the polycomb repressive complex 2 in acute promyelocytic leukemia. Cancer Cell. 2007;11:513-25.

11. van Steensel B, Furlong EEM. The role of transcription in shaping the spatial organization of the genome. Nat Rev Mol Cell Biol. 2019:20:327-37.

12. Gröschel S, Sanders MA, Hoogenboezem R, de Wit E, Bouwman BAM, Erpelinck C, et al. A single oncogenic enhancer rearrangement causes concomitant EVI1 and GATA2 deregulation in leukemia. Cell. 2014;157:369-81.

13. Yamazaki H, Suzuki M, Otsuki A, Shimizu R, Bresnick EH, Engel JD, et al. A remote GATA2 hematopoietic enhancer drives leukemogenesis in inv (3)(q21;q26) by activating EVI1 expression. Cancer Cell. 2014;25:415-27.

14. Hnisz D, Weintraub AS, Day DS, Valton A-L, Bak RO, Li CH, et al. Activation of proto-oncogenes by disruption of chromosome neighborhoods. Science. 2016;351:1454-8.

15. Grignani F, Ferrucci PF, Testa U, Talamo G, Fagioli M, Alcalay M, et al. The acute promyelocytic leukemia-specific PMLRAR alpha fusion protein inhibits differentiation and promotes survival of myeloid precursor cells. Cell. 1993;74:423-31.

16. Tang Z, Luo OJ, Li X, Zheng M, Zhu JJ, Szalaj P, et al. CTCF-mediated human 3D genome architecture reveals chromatin topology for transcription. Cell. 2015;163:1611-27.

17. Yang X-W, Wang P, Liu J-Q, Zhang H, Xi W-D, Jia X-H, et al. Coordinated regulation of the immunoproteasome subunits by PML-RARa and PU.1 in acute promyelocytic leukemia. Oncogene. 2014;33:2700-8.

18. Zheng P-Z, Wang K-K, Zhang Q-Y, Huang Q-H, Du Y-Z, Zhang Q-H, et al. Systems analysis of transcriptome and proteome in retinoic acid/arsenic trioxide-induced cell differentiation/apoptosis of promyelocytic leukemia. Proc Natl Acad Sci. 2005;102:7653-8.

19. Duprez E, Wagner K, Koch H, Tenen DG. C/EBPbeta: a major PML-RARA-responsive gene in retinoic acid-induced differentiation of APL cells. EMBO J. 2003:22:5806-16.

20. Nigten J, Breems-de Ridder MC, Erpelinck-Verschueren CAJ, Nikoloski G, van der Reijden BA, van Wageningen S, et al. ID1 and ID2 are retinoic acid responsive genes and induce a G0/G1 accumulation in acute promyelocytic leukemia cells. Leukemia. 2005:19:799-805.

21. Mueller BU. ATRA resolves the differentiation block in $\mathrm{t}(15 ; 17)$ acute myeloid leukemia by restoring PU.1 expression. Blood. 2006:107:3330-8

22. Nolis IK, McKay DJ, Mantouvalou E, Lomvardas S, Merika M, Thanos D. Transcription factors mediate long-range enhancer-promoter interactions. Proc Natl Acad Sci U S A. 2009:106:20222-7.

23. Zlotorynski E. Gene expression: the yin and yang of enhancer-promoter interactions. Nat Rev Mol Cell Biol. 2018;19:75. 
24. Hnisz D, Abraham BJ, Lee TI, Lau A, Saint-André V, Sigova AA, et al. Super-enhancers in the control of cell identity and disease. Cell. 2013;155:934-47.

25. Pott S, Lieb JD. What are super-enhancers? Nat Genet. 2015;47:8-12.

26. Lovén J, Hoke HA, Lin CY, Lau A, Orlando DA, Vakoc CR, et al. Selective inhibition of tumor oncogenes by disruption of super-enhancers. Cell. 2013;153:320-34.

27. Whyte WA, Orlando DA, Hnisz D, Abraham BJ, Lin CY, Kagey MH, et al. Master transcription factors and mediator establish super-enhancers at key cell identity genes. Cell. 2013;153:307-19.

28. Lanotte M, Martin-Thouvenin V, Najman S, Balerini P, Valensi F, Berger R. NB4, a maturation inducible cell line with t(15; 17) marker isolated from a human acute promyelocytic leukemia (M3). Blood. 1991;77:1080-6.

29. Li G, Ruan X, Auerbach RK, Sandhu KS, Zheng M, Wang P, et al. Extensive promoter-centered chromatin interactions provide a topological basis for transcription regulation. Cell. 2012;148:84-98.

30. Li X, Luo OJ, Wang P, Zheng M, Wang D, Piecuch E, et al. Long-read ChIA-PET for base-pair-resolution mapping of haplotype-specific chromatin interactions. Nat Protoc. 2017:12:899-915.

31. Wang P, Tang ZH, Lee B, Zhu JF, Cai LY, Szalaj P, Tian ZY, Zheng MZ, Plewczynski D, Ruan X, Liu ET, Wei CL, Ruan YJ. Chromatin topology reorganization and transcription repression by PML-RARa in acute promyeloid leukemia. Datasets Gene Expression Omnibus. 2019. https://www.ncbi.nlm.nih.gov/geo/query/acc.cgi?acc=GSE137662. Accessed 5 Dec 2019.

\section{Publisher's Note}

Springer Nature remains neutral with regard to jurisdictional claims in published maps and institutional affiliations.

Ready to submit your research? Choose BMC and benefit from:

- fast, convenient online submission

- thorough peer review by experienced researchers in your field

- rapid publication on acceptance

- support for research data, including large and complex data types

- gold Open Access which fosters wider collaboration and increased citations

- maximum visibility for your research: over $100 \mathrm{M}$ website views per year

At $B M C$, research is always in progress.

Learn more biomedcentral.com/submissions 